\title{
Production of lightweight aggregates from mining residues, heavy metal sludge, and incinerator fly ash
}

\author{
Su-Chen Huang ${ }^{a}$, Fang-Chih Chang ${ }^{b, *}$, Shang-Lien Lo ${ }^{b}$, \\ Ming-Yu Lee ${ }^{c}$, Chu-Fang Wang ${ }^{a}$, Jyh-Dong Lin ${ }^{c}$ \\ ${ }^{a}$ Department of Atomic Science, National Tsing Hua University, 101, Sec. 2, Kuang Fu Road, Hsinchu 300, Taiwan, ROC \\ ${ }^{\mathrm{b}}$ Research Center for Environmental Pollution Prevention and Control Technology, Graduate Institute of Environmental Engineering, \\ National Taiwan University, 71 Chou-Shan Road, Taipei 106, Taiwan, ROC \\ ${ }^{\mathrm{c}}$ Department of Civil Engineering, National Central University, 300 Jhongda Road, Jhongli 320, Taiwan, ROC
}

Received 30 June 2006; received in revised form 26 September 2006; accepted 27 September 2006

Available online 11 October 2006

\begin{abstract}
In this study, artificial lightweight aggregate (LWA) manufactured from recycled resources was investigated. Residues from mining, fly ash from an incinerator and heavy metal sludge from an electronic waste water plant were mixed into raw aggregate pellets and fed into a tunnel kiln to be sintered and finally cooled rapidly. Various feeding and sintering temperatures were employed to examine their impact on the extent of vitrification on the aggregate surface. Microstructural analysis and toxicity characteristic leaching procedure (TCLP) were also performed. The results show that the optimum condition of LWA fabrication is sintering at $1150{ }^{\circ} \mathrm{C}$ for $15 \mathrm{~min}$ with raw aggregate pellets fed at $750{ }^{\circ} \mathrm{C}$. The rapidly vitrified surface envelops the gas produced with the increase in internal temperature and cooling by spraying water prevents the aggregates from binding together, thus forming LWA with specific gravity of 0.6. LWA produced by sintering in tunnel kiln shows good vitrified surface, low water absorption rate below 5\%, and low cylindrical compressive strength of $4.3 \mathrm{MPa}$. In addition, only trace amounts of heavy metals were detected, making the LWA non-hazardous for construction use.
\end{abstract}

(C) 2006 Elsevier B.V. All rights reserved.

Keywords: Artificial lightweight aggregate; Recycling; Heavy metal; Compressive strength; SEM

\section{Introduction}

Since the earthquake forces that influence civil engineering structures and buildings are proportional to their mass, reducing the mass of the structure or building is of utmost importance to ensure its resistance against earthquake disaster. Lightweight structural design can also help reduce the overall construction costs [1]. One way to reduce the mass or dead weight of a structure is to use lightweight concrete in the construction. Kilic et al. [2] had successfully produced lightweight concrete with bulk density of $176.5 \mathrm{MPa}$ and cylindrical compressive strength of $40 \mathrm{MPa}$. Synthetic lightweight aggregate (LWA) manufactured from recycled resources has replaced natural sand and stone in green construction. Widely applied to high-rise structures and

\footnotetext{
* Corresponding author. Tel.: +88622362 5373; fax: +886223928830.

E-mail address: d90541003@ntu.edu.tw (F.-C. Chang).
}

employed as partition wall material, LWA is not only lightweight and fire resistant, but also has good insulation against heat and sound $[3,4]$.

LWA was first manufactured from clay and shale sintered in a rotary kiln in 1917. Under high-temperature heating, certain elements present in the raw materials expand, thus forming a hard vitrified layer on the surface [5]. Since then, sintering of LWA has mainly been performed in a rotary kiln. Sintering sewage sludge ash (SSA) at $1040-1100{ }^{\circ} \mathrm{C}$, Bhatty and Reidt [6] had successfully manufactured LWA with bulk density of $0.8-1.4 \mathrm{~g} / \mathrm{cm}^{3}$ in large quantity and at low cost. Ramamurthy and Harikrishman [7] observed that the properties of sintered aggregates depend on the type of binder and its dosage, and that there is significant improvement in strength and reduction in water absorption when bentonite is added to the sintered aggregates.

Previous studies have described the manufacturing of LWA using natural materials such as clay, shale, perlite, vermiculite, and polystyrene. For example, non-self bloating clays have been 
Table 1

Chemical composition of mining residues, heavy metal sludge, and incinerator fly ash

\begin{tabular}{lccc}
\hline Composition & $\begin{array}{l}\text { Mining } \\
\text { residues }\end{array}$ & $\begin{array}{l}\text { Heavy metal } \\
\text { sludge }\end{array}$ & $\begin{array}{l}\text { Incinerator } \\
\text { fly ash }\end{array}$ \\
\hline Phase oxides (\%) & & & \\
$\mathrm{SiO}_{2}$ & 56.3 & 45.1 & 30.3 \\
$\mathrm{Al}_{2} \mathrm{O}_{3}$ & 14.4 & 13.0 & 10.3 \\
$\mathrm{Fe}_{2} \mathrm{O}_{3}$ & 6.8 & 4.8 & 12.0 \\
$\mathrm{CaO}$ & 5.1 & 19.6 & 33.9 \\
$\mathrm{MgO}$ & 4.2 & 0.9 & 1.2 \\
$\mathrm{~K}_{2} \mathrm{O}$ & 1.6 & 1.2 & 0.3 \\
$\mathrm{Na}_{2} \mathrm{O}$ & 1.4 & 2.1 & 1.5 \\
Others & 10.2 & 13.3 & 10.5 \\
Anions $(\%)$ & & & \\
Sulfate & $<0.2$ & 0.8 & 3.2 \\
Chloride & $<0.2$ & 1.3 & 5.4 \\
Fluoride & $<0.2$ & $<0.2$ & $<0.2$ \\
Phosphate & $<0.2$ & $<0.2$ & 1.6 \\
Nitrate & $<0.2$ & $<0.2$ & $<0.2$ \\
\hline
\end{tabular}

employed to produce LWA with bulk density ranging between 0.16 and $0.85 \mathrm{~g} / \mathrm{cm}^{3}$ and cylindrical compressive strength within the range of $0.78-14.4 \mathrm{MPa}$ [8]. LWA with bulk density of $0.9-1.1 \mathrm{~g} / \mathrm{cm}^{3}$ has also been manufactured using Neapolitan Yellow Tuff [9]. Besides natural resources, waste materials such as fly ash $[7,10]$, glass $[11,12]$, and SSA [13-16] have also been recycled into LWA through sintering.

Research on physical properties of synthetic LWA and lightweight concrete manufactured using recycled materials began in the 1970s. In general, artificial LWA has a unit weight ranging between 0.67 and $2.1 \mathrm{~g} / \mathrm{cm}^{3}$, and shows properties of high porosity, low density, high water absorption, low compressive strength, and low elastic modulus. The aggregate examined in this study is LWA with unit weight below $0.60 \mathrm{~g} / \mathrm{cm}^{3}$. Partition walls made of LWA show specific gravity of around 0.8 [17]. LWA made from SSA $[18,19]$ containing heavy metals can meet the leaching standard for hazardous industrial wastes as specified by the EPA, ROC [20]. In Taiwan, as much as $6.3 \times 10^{4}$ metric tonnes of mining residues, $4.1 \times 10^{5}$ metric tonnes of heavy metal sludge, and $1.5 \times 10^{5}$ metric tonnes of incinerator fly ash were produced per year. Currently, the majority of heavy metal sludge and incinerator fly ash are treated by solidification and subsequent landfill disposal. As yet, there is insufficient data to clear the long-term risk of heavy metal leakage by this method. Currently, several scientists around the world are working on the laboratory production of LWA using clayey raw materials and/or pulverized fuel ash (PFA) or sewage sludge and reservoir sediments. Other authors tried to treat these wastes, but not in particular to produce LWA from them.

The goal of this study is to determine the effects of recycled resources and heating temperature on properties related to bloating effect. Residues from mining, fly ash from an incinerator and heavy metal sludge from an electronic waste water plant were recycled into LWA. Mining residues were used instead of dredge sludge from reservoirs because of their stable chemical composition and low water content. The results of this study provide useful information on co-treating of waste and recycled resources as lightweight aggregates.

\section{Materials and methods}

\subsection{Materials}

Table 1 shows the chemical composition of mining residues, heavy metal sludge, and incinerator fly ash employed in this study. The toxicity characteristic leaching procedure (TCLP) was adopted to determine the leaching concentrations of heavy metals from the sludge, fly ash, and lightweight aggregates. Table 2 displays the analysis results of the total concentrations and leaching concentrations of the fly ash and heavy metal sludge used [20].

\subsubsection{Mining residues}

The residues employed in this study come from a mine in Hualien, Taiwan. The mine mainly produces shale, bentonite, and white clay. Hence, the composition of the mining residues resembles that of shale. As shown in Table 1, the residues comprise mainly silicon dioxide $\left(\mathrm{SiO}_{2}\right)$, followed by aluminum oxide $\left(\mathrm{Al}_{2} \mathrm{O}_{3}\right)$ and iron oxide $\left(\mathrm{Fe}_{2} \mathrm{O}_{3}\right)$ as well as trace amounts of calcium oxide $(\mathrm{CaO})$, magnesium oxide $(\mathrm{MgO})$, potassium oxide $\left(\mathrm{K}_{2} \mathrm{O}\right)$, and sodium oxide $\left(\mathrm{Na}_{2} \mathrm{O}\right)$.

\subsubsection{Fly ash}

The fly ash (APC residue) used is from the municipal waste incinerator in Taipei, Taiwan. As seen in Table 1, the fly ash

Table 2

Total and leaching concentration of heavy metal sludge and fly ash

\begin{tabular}{|c|c|c|c|c|c|}
\hline \multirow[t]{2}{*}{ Heavy metal } & \multicolumn{2}{|c|}{ Total concentration (mg/kg) } & \multicolumn{3}{|c|}{ Leaching concentration (mg/L) } \\
\hline & Heavy metal sludge & Fly ash of incinerator & Heavy metal sludge & Fly ash of incinerator & Regulation $^{\mathrm{a}}$ \\
\hline Lead $(\mathrm{Pb})$ & 8.4 & 1800.0 & 0.5 & 6.3 & 5.0 \\
\hline Copper $(\mathrm{Cu})$ & 95.0 & 1163.0 & 45.2 & 6.1 & 15.0 \\
\hline Zinc (Zn) & $\mathrm{ND}^{\mathrm{b}}$ & 9312.0 & ND & 22.4 & No Limitation \\
\hline Total Chromium (Cr) & 228 & 261.6 & 6.9 & 8.3 & 5.0 \\
\hline Mercury (Hg) & ND & ND & ND & ND & 0.2 \\
\hline
\end{tabular}

\footnotetext{
${ }^{a}$ Ref. [20].

${ }^{b} \mathrm{ND}(<0.002 \mathrm{mg} / \mathrm{L})$.
} 
is composed of $\mathrm{CaO}$, followed by $\mathrm{SiO}_{2}$. However, hazardous heavy metals including zinc $(\mathrm{Zn})$, copper $(\mathrm{Cu})$, chromium $(\mathrm{Cr})$, and lead $(\mathrm{Pb})$ are also present as shown in Table 2.

\subsubsection{Heavy metal sludge cake}

The sludge that was produced from the coagulation and sedimentation of etching and pickling wastewater, using an anionic polymer as a flocculant, was taken from a printed circuit board factory in Taiwan. The sludge materials used in this study were pretreated by chelating extraction (using $0.1 \mathrm{M}$ EDTA). These sludge materials comprise heavy metal hazardous wastes including $\mathrm{Cr}$ and $\mathrm{Cu}$, as seen in Table 2 .

\subsection{LWA preparation}

Fig. 1 shows the schematic profile of the tunnel kiln for sintering LWA. The manufacturing process includes raw material preparation, drying, pulverizing, mixing, pelletization, sintering and cooling. The tunnel kiln is a counter flow kiln because the conveyer sintering system loaded with pellets travels through the kiln (intermittently) in the opposite direction. The tunnel kiln consists of four main zones; pre-heating, feeding, sintering and cooling zones, each $0.5-3 \mathrm{~m}$ long. The pellets entering the pre-heating and feeding zone encounter the hot gases from the downstream sintering zone. Thus, the pellets are heated at $750{ }^{\circ} \mathrm{C}$ and conduce to the rapidly vitrified surface. The pellets continue on to the sintering zone where natural gas is introduced to heat the product to the temperature required to motivate the essential transformation that yields LWA. Then, the hot product moves on to the cooling zone, where it gives off some of its heat to the cooling air as it passes in the opposite direction. This cools the sintered LWA down to the intended exit temperature $\left(60^{\circ} \mathrm{C}\right)$, while the cooling air temperature rises.

\subsubsection{Mixing}

The waste raw materials collected were oven dried at $105^{\circ} \mathrm{C}$ until reaching constant weight. The raw materials were pulverized and sieved to $<0.075 \mathrm{~mm}$ (sieve \#200), and stored in glass containers pending analysis. After going through sieve \#200, the mining residues, fly ash and heavy metal sludge were mixed at a weight ratio of 50\%:25\%:25\%. The analysis of composition showed that the pellets comprised mainly $\mathrm{SiO}_{2}(47 \%)$, followed by $\mathrm{A}_{2} \mathrm{O}_{3}(13 \%)$ and $\mathrm{CaO}(17.5 \%)$, which matches the chemical composition of expandable LWA.

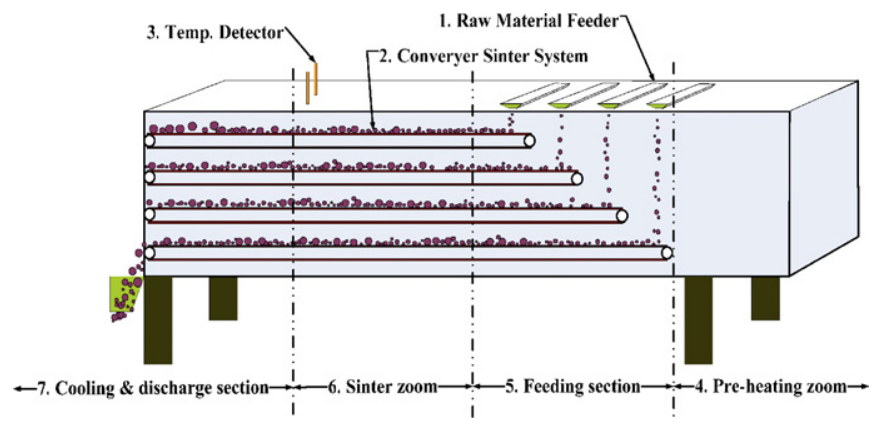

Fig. 1. The schematic profile of the tunnel kiln for sintering LWA.

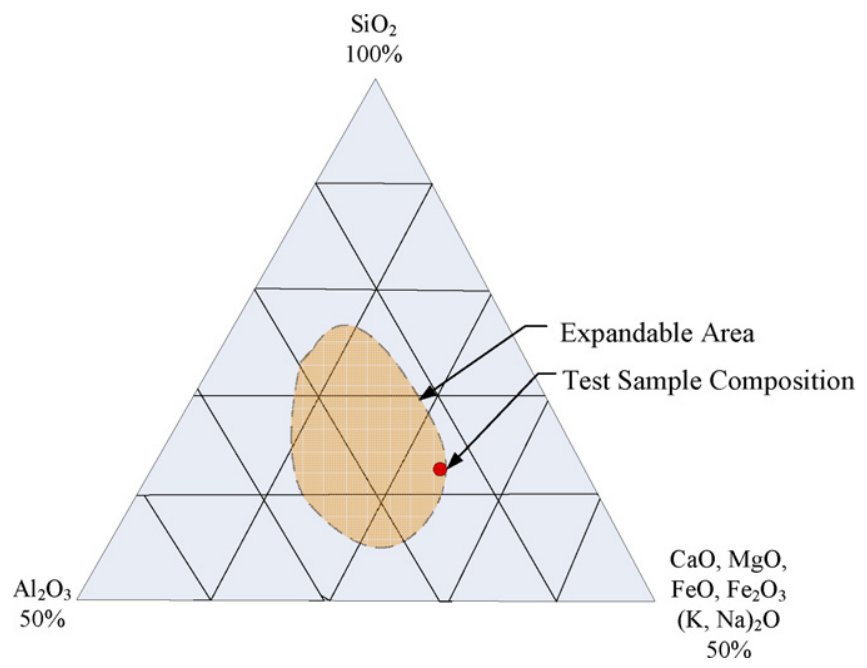

Fig. 2. Ternary plot of LWA.

Fig. 2 shows the region of admixture in the $\mathrm{SiO}_{2}-\mathrm{Al}_{2} \mathrm{O}_{3}-\mathrm{CaO}$ ternary plot. As seen in Fig. 2, the pellets match the chemical composition of expandable LWA.

\subsubsection{Pelletization}

Water and starch at weight percentage of 16 and $0.5 \%$, respectively, were added to the mixture of mining residues, fly ash, and heavy metal sludge as binder for pelletization. The principles of rotary pelletization can be summarized in the following steps: (1) the fine raw material is continuously added to the rotary and wetted by a fine water spray; (2) due to the rotating propelled action of the rotary, the moistened material forms small seed type particles; (3) the seed particles then "snowball" into larger particles until they discharge from the rotary. Basically, typical applications range from disposal to recycling of fine or hard materials. The operating conditions of the granulation step were at $15 \mathrm{~min}, 25^{\circ} \mathrm{C}$, and $15 \mathrm{rpm}$ in the rotary pelletization machine. Raw pellet aggregates of 3-7 mm diameter were made in a rotary pelletization machine and then dried to contain water of 1,5 , and $10 \%$. The role of water is to help to form cavities inside pellets through the gasification of water in high pre-heating processes. However, the pellets would burst in high pre-heating processes when the content of water was more than $10 \%$.

\subsubsection{Sintering}

Sintering can enhance the porosity and strength of ceramic particles while reducing the water absorption rate. To achieve the best result, the particle size and shape, distribution of voids, as well as extent of vitrification must be well controlled. Hence, the sintering temperature is the main determinant of the unit weight of the LWA sintered.

Dried aggregate pellets were fed directly through the raw material inlet at temperatures of 750,850 , and $950^{\circ} \mathrm{C}$ and sintered at $1050,1100,1150,1200$, and $1250^{\circ} \mathrm{C}$ for 5,15 , and 25 min into LWA.

\subsubsection{Cooling}

The sintered LWA was rapidly quenched under sprayed water to below $240^{\circ} \mathrm{C}$ and cooled under ambient air. 


\subsection{Analyses}

The characterization of the recycled resources was performed according to the following chemical and physical measurement methods:

\begin{tabular}{ll}
\hline $\begin{array}{l}\text { Physical and chemical measurement methods } \\
\text { Chemical composition }\end{array}$ & $\begin{array}{l}\text { ICP-AES (inductively coupled plasma } \\
\text { optical emission spectroscopy) }\end{array}$ \\
TCLP tests & NIEA R201.13C (Taiwan) \\
Mechanical tests & ASTM C127 \\
Bulk density & NIEA R207.22C (Taiwan) [21]. Polarizing \\
Cylindrical compressive & microscope, Olympus/Topcon-BX60 \\
strength & SEM (scanning electron microscope), JEOL \\
Microstructural changes & JSM-6300F
\end{tabular}

To evaluate the reproducibility of the results, all experiments were measured using triplicate samples.

\section{Results and discussion}

\subsection{Effect of feeding and sintering temperature}

Fig. 3 displays the curves of sintering temperature for raw materials fed at different high temperatures. When fed at $850^{\circ} \mathrm{C}$ into the tunnel kiln, raw aggregate sintered pellets have their surfaces rapidly vitrified, thus enveloping the gas produced in the process. Increase in temperature will lead to the following: (1) vaporization of sulfur materials at $400{ }^{\circ} \mathrm{C}$, (2) release of water from crystals in the clay at $600^{\circ} \mathrm{C}$, (3) formation of $\mathrm{CO}_{2}$ from carbon compounds at $700^{\circ} \mathrm{C}$, and (4) gas produced under reaction of $\mathrm{Fe}_{2} \mathrm{O}_{3}$ at $1100^{\circ} \mathrm{C}$. The reactions involved are

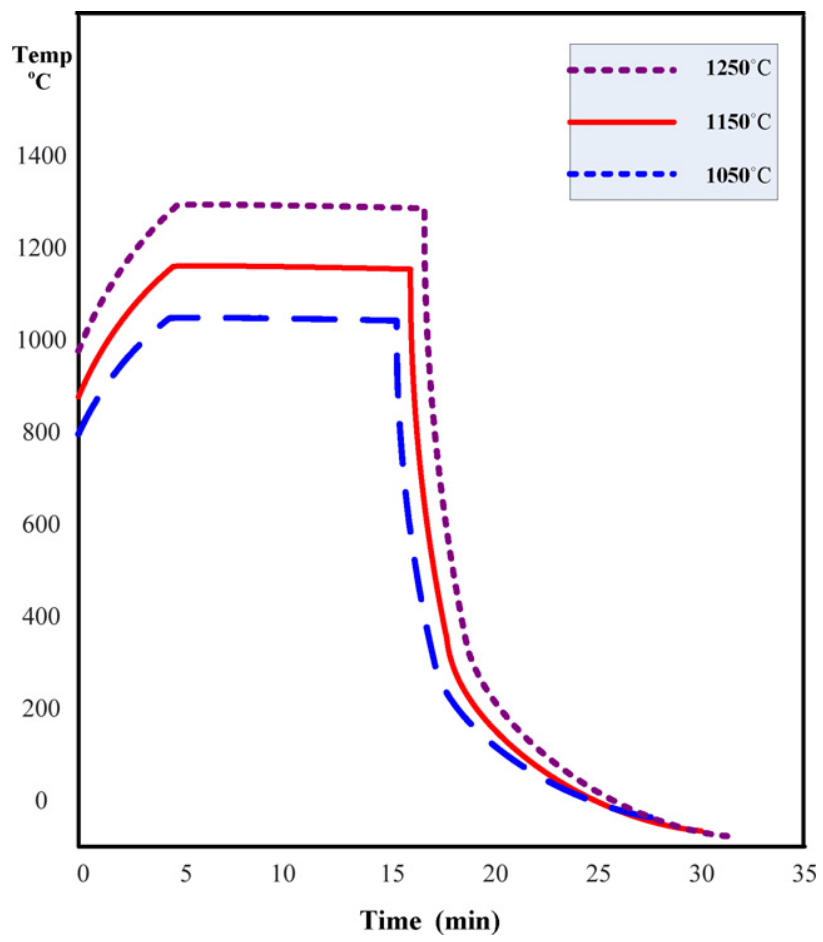

Fig. 3. Sintering temperature for raw materials fed at different temperatures.
Table 3

Specific gravity achieved at different feeding and sintering temperatures

\begin{tabular}{llllll}
\hline Specific gravity & \multicolumn{5}{l}{ Sintering temperature $\left({ }^{\circ} \mathrm{C}\right)$} \\
\cline { 2 - 6 } & 1050 & 1100 & 1150 & 1200 & 1250 \\
\hline Feeding temperature $\left({ }^{\circ} \mathrm{C}\right)$ & 0.97 & 0.80 & 0.61 & 0.66 & 0.73 \\
750 & 0.88 & 0.65 & 0.48 & 0.72 & 0.85 \\
850 & - & - & - & - & - \\
950 &
\end{tabular}

represented by $6 \mathrm{Fe}_{2} \mathrm{O}_{3} \rightarrow 4 \mathrm{Fe}_{3} \mathrm{O}_{4}+\mathrm{O}_{2}$ and $\mathrm{FeS}_{2} \rightarrow \mathrm{FeS}+\mathrm{S}$, $\mathrm{S}+\mathrm{O}_{2} \rightarrow \mathrm{SO}_{2}$, and $2 \mathrm{FeS}+3 \mathrm{O}_{2} \rightarrow 2 \mathrm{FeO}+2 \mathrm{SO}_{2}$. Owing to the low thermal conductivity, the LWA has the greatest amount of gas produced when heated at $1150^{\circ} \mathrm{C}$ for $10 \mathrm{~min}$.

When the feeding temperature is too low, the raw aggregate pellets will experience temperature increase, both internal and external, during sintering. The surface is not completely vitrified when gas is produced, making it possible for gas to escape. This not only increases porosity but also water absorption, thus undermining the engineering properties of the LWA thus manufactured. On the other hand, at feeding temperature of $950{ }^{\circ} \mathrm{C}$, the water in the crystals is rapidly released in large quantity, causing the pellets to burst and thus increasing the rate of defects. For raw aggregate pellets fed at ambient temperature, their small size (diameter below $10 \mathrm{~mm}$ ) causes the temperature at the cen-

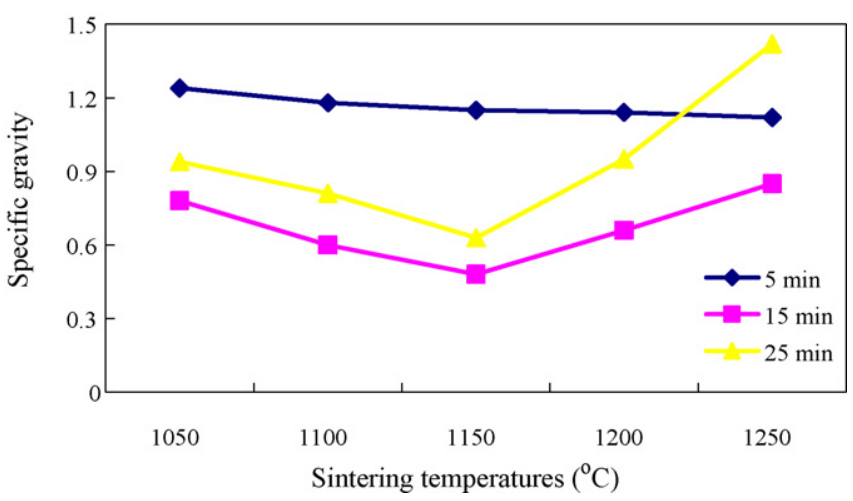

Fig. 4. Relationship between sintering duration and specific gravity at different sintering temperatures.

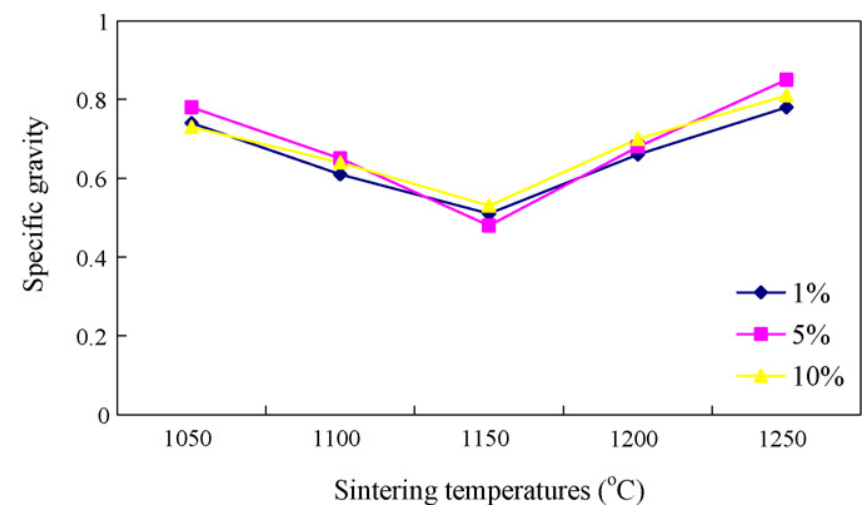

Fig. 5. Relationship between water content and specific gravity at different sintering temperatures for $15 \mathrm{~min}$. 
ter to rise together with the kiln temperature. As a result, all the internal gas is released before the surface becomes completely vitrified, thus affecting the quality of the LWA produced. Our results reveal that the lowest specific gravity of LWA is fabricated at sintering of $1150{ }^{\circ} \mathrm{C}$ for $15 \mathrm{~min}$ with raw aggregate pellets fed at $750{ }^{\circ} \mathrm{C}$. The rapidly vitrified surface envelops the gas produced with the increase in internal temperature resulting in a specific gravity of 0.6 , shown in Table 3 . As can be seen in Table 3 , at feeding temperature of $850^{\circ} \mathrm{C}$, the LWA sintered at $1150{ }^{\circ} \mathrm{C}$ has specific gravity below 0.5 . Further increase in feeding temperature to $950^{\circ} \mathrm{C}$ leads to rapid vaporization of moisture, causing the pellets to burst.

\subsection{Effect of sintering duration}

Fig. 4 shows the specific gravity of LWA sintered at different temperatures and for different duration. As can be seen, specific gravity is the highest when sintering is performed for $5 \mathrm{~min}$. Such short duration does not allow the reaction to complete and the gas produced is not sufficient to create voids in the aggregates. Hence, the LWA has specific gravity of 1.12-1.24, which resembles that of raw aggregate pellets. On the other hand, sintering for 25 min causes total melting of the aggregates and the specific gravity quickly increases to 1.42 , far from that required of LWA. Our results reveal that the lowest spe-

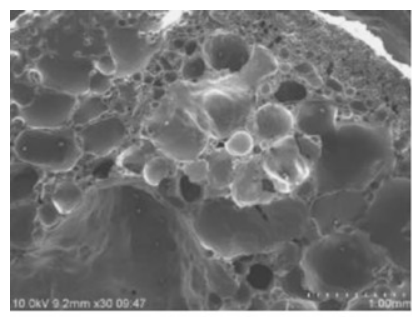

(a) SEM image of LWA

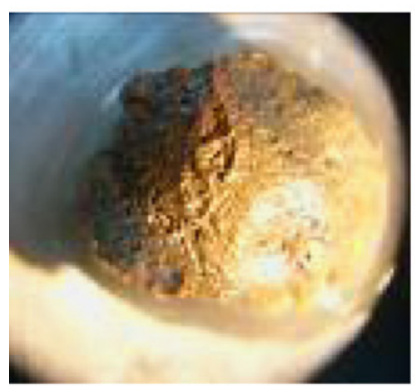

$400 \mu \mathrm{m}$

(d) Surface vitrified at $1050^{\circ} \mathrm{C}$

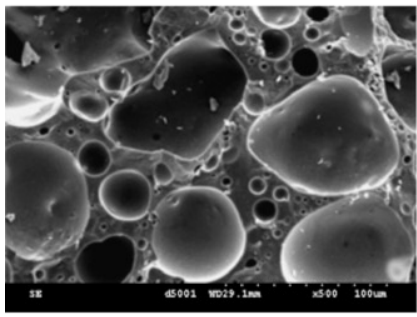

(g) Pores formed at SG 0.5

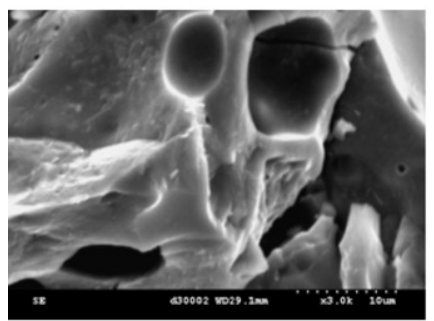

(j) Feeding temperature at $750^{\circ} \mathrm{C}$ (no $\mathrm{CaO}$ observed)

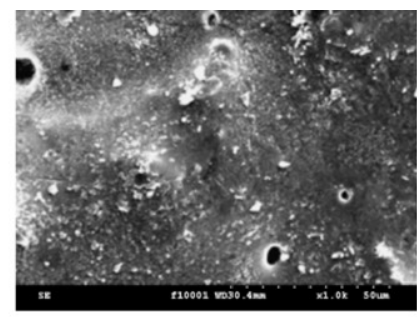

(b) LWA sintered at $1050^{\circ} \mathrm{C}$

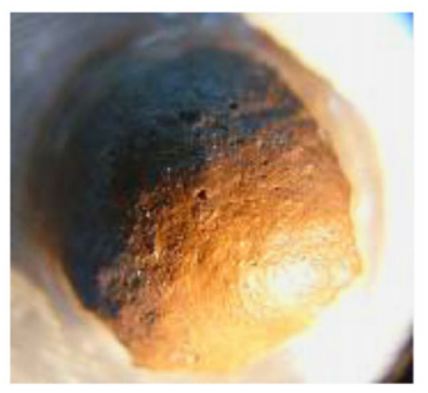

$400 \mu \mathrm{m}$

(e) Surface vitrified at $1150^{\circ} \mathrm{C}$

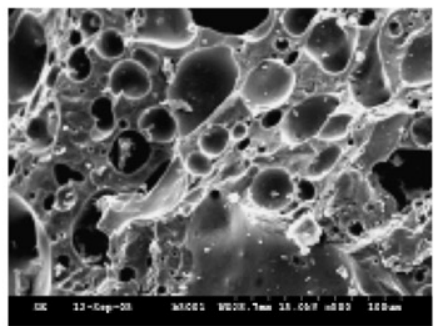

(h) Pores formed at SG 1.0

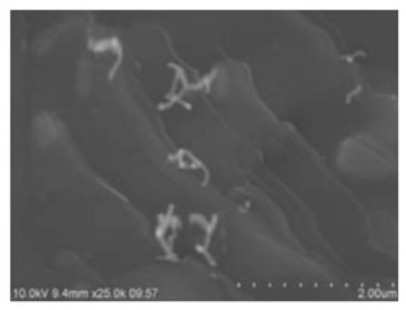

(k) Feeding temperature at $850^{\circ} \mathrm{C}$ (strings of $\mathrm{CaO}$ deposits)

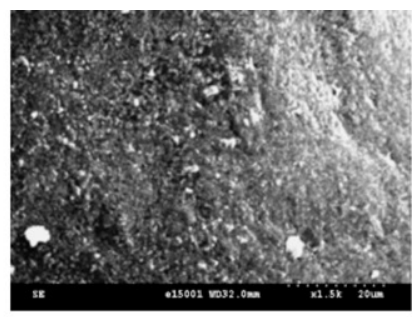

(c) LWA sintered at $1250^{\circ} \mathrm{C}$

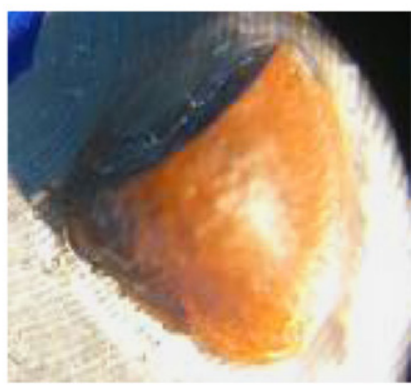

$400 \mu \mathrm{m}$

(f) Surface vitrified at $1250^{\circ} \mathrm{C}$

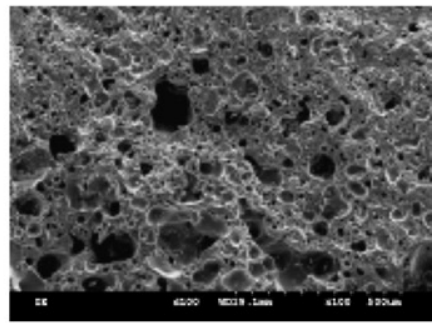

(i) Pores formed at SG 1.5

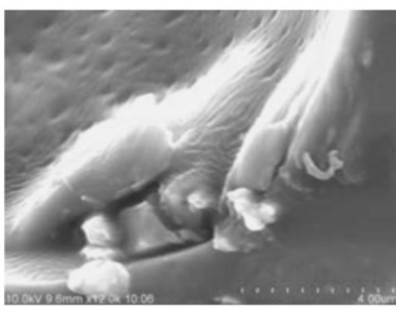

(1) Feeding temperature at

$950^{\circ} \mathrm{C}$ (deposition of $\left.\mathrm{CaO}\right)$

Fig. 6. SEM images of sintered LWA (SG: specific gravity). 
cific gravity of 0.48 can be achieved by sintering at $1150{ }^{\circ} \mathrm{C}$ for 15 min.

\subsection{Effect of water content}

Fig. 5 plots the relationship between water content in the dried raw aggregates and specific gravity achieved at different sintering temperatures for $15 \mathrm{~min}$. As can be seen, the three curves are close to each other, implying that there is no difference in specific gravity obtained for aggregates containing 1,5 , and $10 \%$ moisture. They all show a decrease in specific gravity with increasing sintering temperature, but then rise again when melting occurs at high temperature. In summary, water content does not play a significant role in determining the specific gravity of the LWA.

\subsection{Microstructure of LWA}

Fig. 6(a)-(i) shows SEM images of LWA under various conditions. As seen in LWA sintered at $1150{ }^{\circ} \mathrm{C}$ (Fig. 6(a)), there are abundant pores present in the center, which are even and with thin boundary, while away from the center, the pores become smaller and more densified. Comparing the images in Fig. 6(b) and (c) reveals that the higher the sintering temperature, the smaller and fewer the pores. The size and quantity of pores are the chief determinants of water absorption rate. Our results show that LWA sintered at high feeding temperature had a water absorption rate ranging from 4 to $9 \%$. Water absorption rate below $10 \%$ indicates that the surface of the LWA has been well vitrified.

Besides better porosity, the aggregate surface also is glossier when vitrification is more complete at higher sintering temperature. As shown in Fig. 6(d)-(f), the color of the vitrified surface changed from yellowish to shiny brown.

Fig. 6(g)-(i) shows the amount of pores formed in LWA of different specific gravity. As can be seen, the higher the specific gravity, the fewer the pores formed. Hence, LWA with specific gravity of 0.5 meets the engineering requirements for making lightweight partition walls.

Fig. 6(j)-(l) are images of LWA sintered at different feeding temperatures with deposits thus formed. Elemental analysis reveals that the deposits were $\mathrm{CaO}$. Feeding at high temperature resulted in immediate vitrification with no air pores formed. As a result, gas from the raw materials could not escape; when cooled, the gas formed string deposits in the voids. It was found that the higher the feeding temperature, the greater the deposition of $\mathrm{CaO}$ and the more densified the LWA.

\subsection{Mechanical and chemical properties of LWA}

The LWA obtained in this study has bulk density between 0.2 and $0.8 \mathrm{~g} / \mathrm{cm}^{3}$ and cylindrical compressive strength ranging from 4.3 to $7.5 \mathrm{MPa}$, shown in Fig. 7. As can be seen, LWA sintered at $1050^{\circ} \mathrm{C}$ had not fully expanded while that sintered at $1250^{\circ} \mathrm{C}$ had aggregates melted with less voids formed. Both conditions resulted in higher cylindrical compressive strength than that of LWA sintered at the optimum temperature of $1150^{\circ} \mathrm{C}$, which achieved the lowest cylindrical compressive strength of 4.3 MPa.

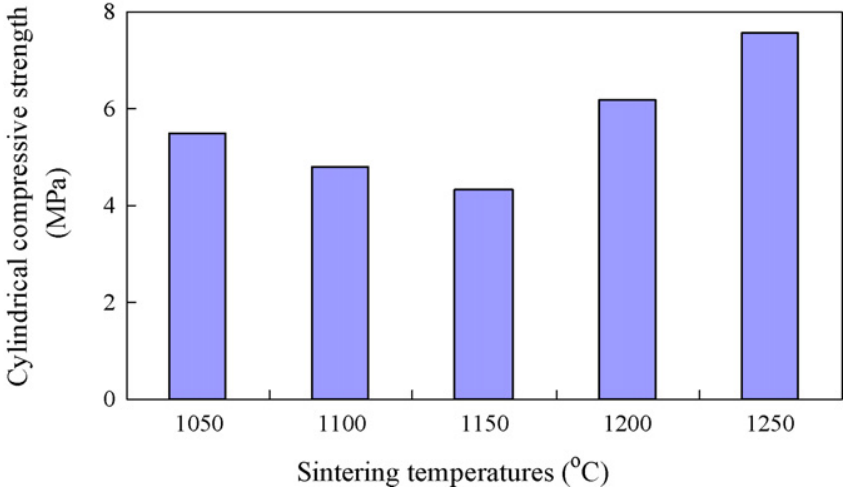

Fig. 7. Relationship between cylindrical compressive strength and sintering temperature.

Table 4

TCLP results of heavy metals

\begin{tabular}{llllll}
\hline Sintering temperature $\left({ }^{\circ} \mathrm{C}\right)$ & \multicolumn{6}{l}{ Leaching concentration $(\mathrm{mg} / \mathrm{L})$} \\
\cline { 2 - 6 } & $\mathrm{Cr}(\mathrm{III})$ & $\mathrm{Cr}$ & $\mathrm{Cd}$ & $\mathrm{Cu}$ & $\mathrm{Pb}$ \\
\hline 1050 & 3.49 & 13.20 & 0.11 & 0.94 & 0.02 \\
1100 & 2.10 & 4.32 & 0.02 & 0.65 & $\mathrm{ND}$ \\
1150 & 0.03 & 0.19 & $\mathrm{ND}^{\mathrm{a}}$ & 0.16 & $\mathrm{ND}$ \\
1200 & $\mathrm{ND}$ & 0.05 & $\mathrm{ND}$ & $\mathrm{ND}$ & $\mathrm{ND}$ \\
1250 & $\mathrm{ND}$ & 0.11 & $\mathrm{ND}$ & $\mathrm{ND}$ & $\mathrm{ND}$ \\
\hline
\end{tabular}

${ }^{\text {a }} \mathrm{ND}(<0.002 \mathrm{mg} / \mathrm{L})$.

Table 4 shows the TCLP results of the LWA manufactured in this study. As can be seen, the higher the sintering temperature, the smaller the amount of heavy metals leached. At sintering temperature exceeding $1150^{\circ} \mathrm{C}$, only trace amounts of $\mathrm{Cr}(\mathrm{VI})$, $\mathrm{Cr}$ and $\mathrm{Cu}$ were detected but not $\mathrm{Cd}$ and $\mathrm{Pb}$; and at $1250^{\circ} \mathrm{C}$, there were no leached heavy metals detected, implying that the LWA thus fabricated is non-hazardous for construction use.

\section{Conclusions}

The object of this study is to recycle mining residues, incinerated fly ash, and heavy metal sludge into LWA. The results of these experiments have led us to conclude the following:

(1) The LWA fabricated in this study has a unit weight of $0.5-1.6 \mathrm{~g} / \mathrm{cm}^{3}$ and specific gravity of 0.5 , which meet the requirements for use in making lightweight partition walls.

(2) TCLP results show that less heavy metals leach with increasing sintering temperature. Above sintering temperature of $1150{ }^{\circ} \mathrm{C}$, the aggregates made from heavy metal sludge become non-hazardous with only trace amounts of heavy metals detected and meet the requirements of the Environment Protection Agency of Taiwan.

(3) Sintering in a tunnel kiln with raw aggregate pellets fed at high temperature can rapidly vitrify the surface of the aggregates, thus producing LWA. Fabricating artificial aggregates through the recycling of waste resources not only provides a practical alternative to the shortage of natural aggregates, but also offers an ecological solution to waste management, both contributing to resource recycling. 


\section{References}

[1] W.M. Lin, Economic assessment of applied structure light weight aggregate concrete, Civil Eng. Technol. 3 (4) (2000) 152-164.

[2] A. Kilic, C.D. Atis, E. Yasar, F. Ozcan, High-strength lightweight concrete made with scoria aggregate containing mineral admixtures, Cement Concrete Res. 33 (10) (2003) 1595-1599.

[3] Y.W. Lieu, H.Q. Chen, J.W. Tan, The insulation performance of light weight aggregate concrete, in: Proceeding of the 1st conference on Lightweight Aggregate and Lightweight Aggregate Concrete, Taiwan Lightweight Aggregate Concrete Association, Taichung, Taiwan, 2003, pp. 83-98.

[4] J.W. Tan, C. Yen, Assessment of insulation and energy conservation of steel structure light weight aggregate concrete building, in: Proceeding of the 1st conference on Lightweight Aggregate and Lightweight Aggregate Concrete, Taiwan Lightweight Aggregate Concrete Association, Taichung, Taiwan, 2003, pp. 117-135.

[5] A. Short, W. Kinniburgh, Lightweight Concrete, Building Research Establishment, Garston Watford, UK, 1976.

[6] J.I. Bhatty, K.J. Reidt, Moderate strength concrete from lightweight sludge ash aggregate, Cement Compos. Lightweight Concrete 11 (3) (1989) 179-187.

[7] K. Ramamurthy, K.I. Harikrishnan, Influence of binders on properties of sintered fly ash aggregate, Cement Concrete Compos. 28 (1) (2006) 33-38.

[8] L.S. Pioro, I.L. Pioro, Production of expanded-clay aggregate for lightweight concrete from non-selfbloating clays, Cement Concrete Compos. 26 (6) (2004) 639-643.

[9] R. de Gennaro, P. Cappelletti, G. Cerri, M. de Gennaro, M. Dondi, A. Langella, Neapolitan Yellow Tuff as raw material for lightweight aggregates in lightweight structural concrete production, Appl. Clay Sci. 28 (2005) 309-319.

[10] G. Baykal, A.G. Doven, Utilization of fly ash by pelletization process; theory, application areas and research results, Resour. Conserv. Recycl. 30 (1) (2000) 59-77.
[11] V. Ducman, M. Kovacevic, High porosity granules produced from waste glass, Kovine Zlitine Tehnol. 33 (5) (1999) 377-379.

[12] V. Ducman, A. Mladenovic, J.S. Suput, Lightweight aggregate based on waste glass and its alkali-silica reactivity, Cement Concrete Res. 32 (2) (2002) 223-226.

[13] J.H. Tay, W.K. Yip, Sludge ash as lightweight concrete material, J. Environ. Eng. 115 (1) (1989) 56-64.

[14] J.H. Tay, W.K. Yip, K.Y. Show, Clay-blended sludge as lightweight aggregate concrete material, J. Environ. Eng. 117 (6) (1991) 834844.

[15] J.H. Tay, K.Y. Show, Resource recovery of sludge as a building and construction material-a future trend in sludge management, Water Sci. Technol. 36 (11) (1997) 259-266.

[16] C.R. Cheeseman, G.S. Virdi, Properties and microstructure of lightweight aggregate produced from sintered sewage sludge ash, Resour. Conserv. Recycl. 45 (2005) 18-30.

[17] H.Q. Chen, C. Yen, Study on impact of roasting characteristic of light weight aggregate imposed by dam silt additive, J. Chung-Hsin Univ. Eng. 14 (2) (2003) 107-114.

[18] K.S. Wang, C.J. Tseng, I.J. Chiou, M.H. Shihb, The thermal conductivity mechanism of sewage sludge ash lightweight materials, Cement Concrete Res. 35 (4) (2005) 803-809.

[19] C.C. Tsai, K.S. Wang, I.J. Chiou, Effect of $\mathrm{SiO}_{2}-\mathrm{Al}_{2} \mathrm{O}_{3}-$ flux ratio change on the bloating characteristics of lightweight aggregate material produced from recycled sewage sludge, J. Hazard. Mater. 134 (2006) 87-93.

[20] Toxicity Characteristic Leaching Procedure, Test Methods for Evaluating Solid Waste, NIEA R201.13C, Environmental Protection Agency, ROC, 2003.

[21] Compressive Strength of Cylindrical Concrete Specimens, Test Methods for Evaluating Solid Waste, NIEA R207.22C, Environmental Protection Agency, ROC, 2005. 